(2) Open Access Full Text Article

ORIGINAL RESEARCH

\title{
Sex disparities in the epidemic of type 2 diabetes in Mexico: national and state level results based on the Global Burden of Disease Study, 1990-2017
}

This article was published in the following Dove Press journal:

Diabetes, Metabolic Syndrome and Obesity: Targets and Therapy

\section{Claudio Alberto \\ Dávila-Cervantes \\ Marcela Agudelo-Botero ${ }^{2}$ \\ 'Latin American Faculty of Social \\ Sciences, Mexico City, Mexico; ${ }^{2}$ Politics, Population and Health Research Center, School of Medicine, National Autonomous University of Mexico, Mexico City, Mexico}

Purpose: To analyze the type 2 diabetes (T2D) health burden in Mexico by sex at the national and state levels from 1990 to 2017.

Methods: This was a secondary analysis based on data from the Global Burden of Disease Study, 1990-2017. We used the indicators of mortality rates, years of life lost due to premature mortality (YLLs), years lived with disability (YLDs), and disability-adjusted life years (DALYs).

Results: At the national level, there was an increase in the standardized mortality rates, YLLs, YLDs and DALYs, especially in the male group. At the state level, the health impacts of T2D varied within the population and did not exhibit any clearly defined geographic pattern. However, the most pronounced increases in the various indicators occurred in the poorer states of the country.

Conclusion: T2D continues to have a dominant impact on Mexican public health, with marked disparities between the states. Working to reduce these health inequalities is necessary, and resources must be focused on the priority groups, for example, men, young and middle-aged adults, and individuals living in the states with the highest index of marginalization.

Keywords: type 2 diabetes, morbidity, mortality

\section{Introduction}

The incidence of type 2 diabetes (T2D) has been increasing for the last 30 years and is now the primary cause of morbidity and mortality worldwide. ${ }^{1,2}$ Globally, it is estimated that $8.8 \%$ of those over 18 years old - more than 450 million peoplelive with diabetes. Of those, $80 \%$ live in middle- and low-income countries. ${ }^{3}$ The number of people with T2D is expected to increase to over 693 million by $2045 .^{3}$ In 2012 alone, diabetes caused 1.5 million deaths worldwide, 43\% of which occurred in individuals younger than 70 years of age. ${ }^{4}$

T2D is a complex chronic disorder that increases the risk of premature death and decreases the quality of life of those who suffer from it. ${ }^{4}$ The impact of T2D is observed because of the high levels of associated mortality and disability and the medical costs of treating the disease and its complications. ${ }^{5}$ Diabetes risk factors are divided into those that are modifiable (such as being overweight or obese, having poor eating habits, smoking and lacking physical exercise) and those that are

Correspondence: Marcela AgudeloBotero

Politics, Population and Health Research Center, School of Medicine, National Autonomous University of Mexico,

Circuito Centro Cultural 20, Insurgentes Cuicuilco, Coyoacán, Mexico City 04510, Mexico

Tel +52 I 5543745473

Email magudelo@comunidad.unam.mx 
nonmodifiable (such as ethnic origin, genetic predisposition and age). ${ }^{3,4}$ The most frequent complications of T2D include heart attacks, strokes, kidney failure, lower limb amputations, loss of visual acuity, and neuropathy. ${ }^{4}$ The annual global cost associated with diabetes is over US $\$ 827$ billion dollars. ${ }^{6}$

In the Americas, the data indicate that close to 62 million people live with T2D. This figure has tripled in the last decade and now represents $15 \%$ of the entire Latin American population 18 years of age or older. ${ }^{7}$ Among Latin American countries, Mexico has the highest T2D mortality rate. ${ }^{8-10}$ The prevalence of diabetes has increased progressively, ${ }^{11,12}$ and diabetes was the principal cause of death in 2017 , with 106,508 deaths attributed to diabetes. ${ }^{13}$ The prevalence of T2D in adults 20 and older increased from $7.2 \%$ in 2006 to $9.2 \%$ in $2012,{ }^{12,14}$ to $9.4 \%$ in 2016. ${ }^{15}$ Healthcare costs associated with diabetes, including direct and indirect costs as well as those incurred as a result of T2D complications, in Mexico have increased to over US $\$ 3.43$ billion dollars. ${ }^{11}$

While there are many studies of T2D in Mexico, there is little research about the behavior and dynamics of the epidemic at the state level, at which the demographic and epidemiological transitions have proceeded unevenly. ${ }^{10}$ Other studies have offered general overviews of the situation by analyzing diabetes and other diseases without going deeper into the particularities that occur at the subnational level. The objective of this study is to analyze the T2D health burden in Mexico by sex at the national and state levels. The study analyzed all 32 Mexican states during the period from 1990 to 2017 and used the indicators of mortality rates, years of life lost due to premature mortality (YLLs), years lived with disability (YLDs), and disability-adjusted life years (DALYs).

\section{Methods}

We performed a secondary analysis based on data from the Global Burden of Disease Study 2017 (GBD), a project of the Institute for Health Metrics and Evaluation at the University of Washington. ${ }^{9}$ The objective of the GBD is to quantify health loss caused by diseases, injuries and risk factors at a local, national, regional and global level. ${ }^{16}$ The GBD uses a standardized, analytical approach that estimates incidence, prevalence and YLDs by year, sex, cause and location. ${ }^{9,16}$ In 2017, the GBD included 195 countries and territories and subnational disaggregated data from 16 countries, using information beginning in 1990. The GBD included 359 diseases and injuries and 84 risks or combinations of risks. ${ }^{17-19}$ The GBD makes use of many sources of information, including censuses, surveys, hospital and administrative registries, and verbal autopsies. ${ }^{16}$ The GBD uses standardized and replicable methods that comply with the Guidelines for Accurate and Transparent Health Estimates Reporting (GATHER). ${ }^{17-19}$

In the present analysis, only T2D is considered, so the data are restricted to people aged 15 or older, given that the evidence suggests that this type of diabetes is beginning to occur at younger ages. ${ }^{18}$ The information, dating from 1990 to 2017, was disaggregated nationally, by state, and by sex and age groups. In this study, mortality, YLLs, YLDs and DALYs rates are presented. To describe the level of confidence for each indicator (given the uncertainty present in the initial data and subsequent calculations), the GBD derived 95\% uncertainty intervals (UI). All rates reported here are age-standardized.

YLLs are a measure of premature death. We calculated the YLLs by multiplying the number of deaths from T2D in each age group by the average life expectancy at the age at which the death occurred. ${ }^{18}$ The GBD in 2017 used a standard life expectancy taken from the lowest observed risk of death for each five-year age group in all populations greater than 5 million. ${ }^{18}$ YLDs were calculated as the product of the estimated prevalence of diabetes and a comorbidity-adjusted disability weight. ${ }^{17}$ The disability weights were obtained using DisMod-MR 2.1, a Bayesian meta-regression tool that produces estimates of incidence, prevalence, remission, excess mortality and the cooccurrence of different diseases and injuries. The DALYs quantify the health loss due to diabetes by measuring the difference between a current situation and an ideal situation in which everyone lives to the age of the standard life expectancy and in perfect health. The DALYs were calculated by adding the YLLs and the YLDs. Details on these indicators can be found in previous publications..$^{10,16-19}$

\section{Results \\ National overview}

T2D has been among the leading causes of death in Mexico. In 1990, T2D deaths represented 5.8\% $(25,198)$ of the total deaths that year. By 2017, T2D deaths constituted $9.0 \%(64,067)$ of the total deaths (data not shown). This increase can also be seen in the mortality rates of both women and men (Figure 1).

Overall, the mortality rate (per 100,000 inhabitants) increased from 45.4 deaths (95\%, UI 43.9-48.2) in 1990 


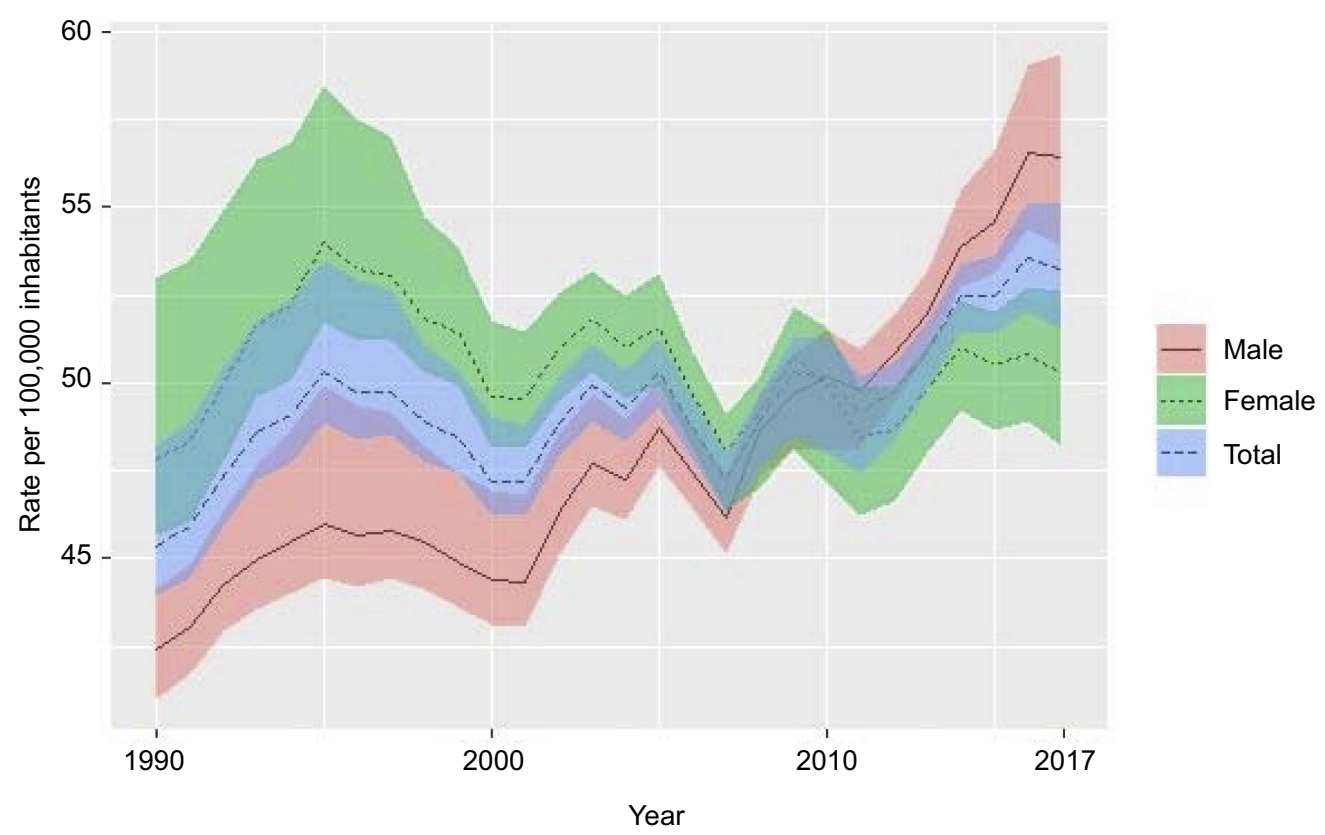

Figure I Age-standardized mortality rate due to type 2 diabetes, by sex; Mexico, 1990-2017. The shaded parts correspond to $95 \%$ uncertainty intervals.

to $53.2(95 \%$, UI 51.5-55.1) in 2017 (a relative change of $29.5 \%$ ). However, the male mortality rate increased by a greater proportion than the female mortality rate (49.6\% versus 9.7\%). Although the $\mathrm{T} 2 \mathrm{D}$ mortality rate was higher for women in 1990, from 2012 to 2017, this pattern was reversed. For males, the mortality rate increased in all age groups, especially in the groups between 20-29 and 35-44 years of age. Women between 20 and 44 years of age had significant increases in the mortality rate, while the mortality rate of women between 55 and 74 years of age was reduced (Figure 2).

In 1990, deaths from T2D translated into 406,183 (95\%, UI 392,005-440,054) YLLs, a number that tripled to $1,231,828(95 \%$, UI $1,189,260-1,275,772)$ in 2017 . The highest number of YLLs from T2D occurred in adults and older adults from 50 to 74 years old. Of the total YLLs, $66.1 \%$ were concentrated in this age group. The YLLs increased throughout the entire period, with a greater

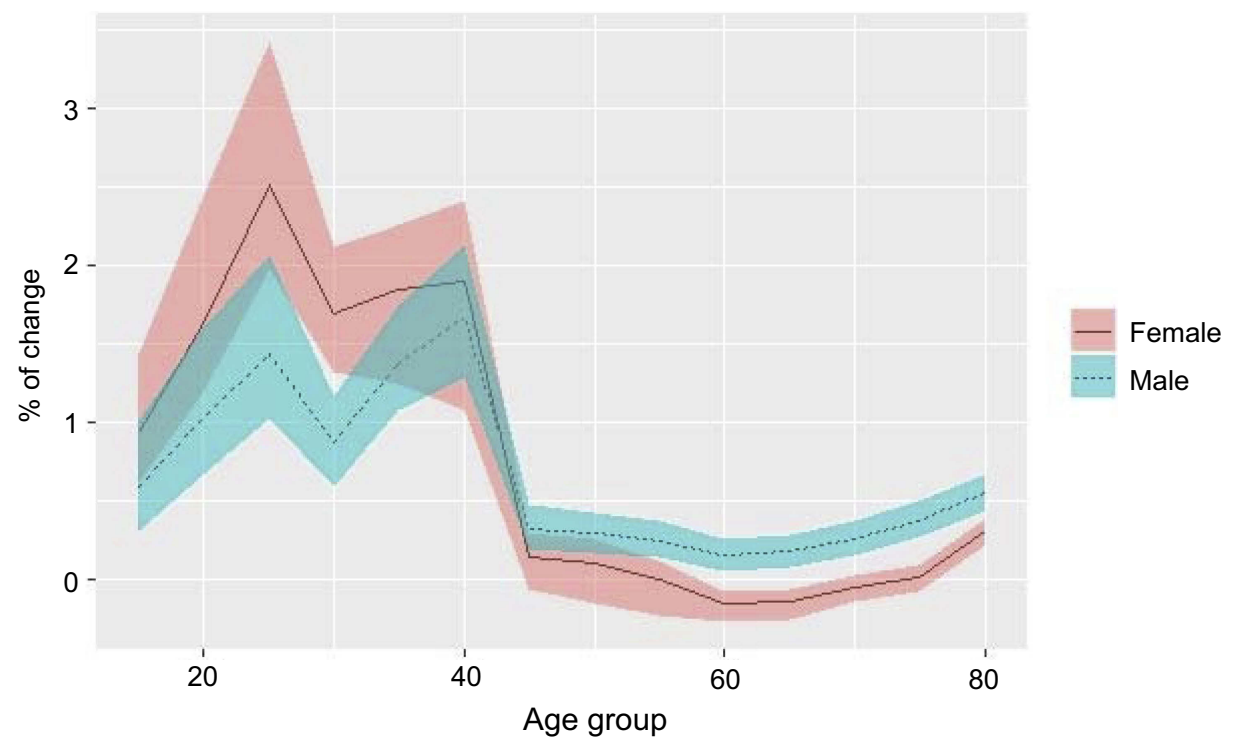

Figure 2 Percentage of change in age-standardized mortality rate due type 2 diabetes in Mexico, by sex and age group between 1990 and 2017 . The shaded parts correspond to $95 \%$ uncertainty intervals. 
increase in men (31.4\%) than in women (2.5\%). T2D is also one of the principal causes of disability in Mexico. By 2017, the YLDs had increased to $1,203,009$ (95\%, UI 814,567-1,672,877) years, 2.7-times more than the 443,943 (95\%, UI $301,391-610,852)$ years registered in 1990 . Compared to the YLLs, the YLDs in 2017 originated mainly from younger age groups $-67.8 \%$ were from individuals aged 40 to 69 years old. During the period examined in this study, the YLDs rate increased consistently, both for men $(22.7 \%)$ and women (10.6\%), and the DALYs rate was higher for men, except for three years (1995-1997). The YLLs, YLDs and DALYs rates by sex are shown in Table 1 .

\section{Subnational overview}

In 1990 and 2017, Coahuila had the highest T2D mortality rate in men. However, the state with the highest female T2D mortality rate in 1990 was Colima, and in 2017, it was Quintana Roo. Although in the great majority of the states, the male mortality rate increased during the study period, in Aguascalientes, Baja California, Colima, Durango and Oaxaca, the rate decreased. However, in ten of the 32 states, the increase was greater than $50 \%$, and even in Chiapas and Guerrero, the change was over $100 \%$. These two areas, together with Quintana Roo, had a marked increase in the T2D mortality rate (greater than $50 \%$ ) for women, which contrasts with thirteen states, mainly Baja California, Nuevo León, Colima and Sonora, in which the rate was reduced (Figure 3).
When considering premature deaths and disability jointly, we found that Tabasco and Mexico City were the regions that had the highest DALYs rate in 2017, while Sinaloa and Nuevo León had the lowest. The most pronounced increases in this rate occurred in Chiapas (67.8\%), Quintana Roo (62.5\%), Guerrero (60.8\%), Tabasco (46.2\%) and Oaxaca (42.9\%) - all of them located in the southeastern and southern regions of the country. Likewise, in 2017, in two-thirds of the national territory, except for states such as Aguascalientes, Baja California Sur, Durango, Hidalgo, Nayarit, Nuevo Leon, Oaxaca, Querétaro, San Luis Potosí, Sinaloa and Yucatán, the YLLs rate was higher than the YLDs rate. However, in eleven states (Aguascalientes, Baja California, Baja California Sur, Chihuahua, Coahuila, Durango, Nayarit, Nuevo Leon, Sinaloa, Sonora and Tamaulipas) the YLL rate decreased, contrary to what happened with the YLDs rate that increased in all states, except Coahuila where it was reduced by only $0.5 \%$ (Figure 4 ).

Table 2 shows the YLLs and YLDs rates disaggregated by sex and state. In general, the male YLLs rate decreased between 1990 and 2017 in some states, such as Aguascalientes, Baja California, Coahuila, Durango and Nuevo Leon, while the female YLLs rate decreased in slightly more than half of the states in that same period. In states such as Chiapas, Guerrero, Oaxaca and Quintana Roo, the YLLs rate increased for both sexes (by more than $85 \%$ in

Table I Age-standardized YLLs, YLDs and DALYs rates due type 2 diabetes in Mexico, 1990-2017, by sex

\begin{tabular}{|c|c|c|c|}
\hline \multirow[t]{2}{*}{ Year } & Rate YLLs (95\% UI) & Rate YLDs (95\% UI) & Rate DALYs (95\% UI) \\
\hline & \multicolumn{3}{|l|}{ Male } \\
\hline 1990 & $893.63(863.60-933.95)$ & $865.73(593.8 \mathrm{I}-1 \mid 94.36)$ & $\mid 759.37(|474.3|-2095.0 \mid$ \\
\hline 1995 & $957.35(924.18-1053.05)$ & $916.44(628.95-1270.61)$ & $1873.80(1570.22-2227.15)$ \\
\hline 2000 & $928.78(901.07-995.14)$ & $908.85(624.5 I-1264.12)$ & $\mid 837.65(|54| .25-2 \mid 83.68$ \\
\hline 2005 & $1013.58(989.86-1050.67)$ & $881.46(599.66-1217.34)$ & |895.05 (|6| |.78-228.80) \\
\hline 2010 & 1040.11 (998.33-1066.99) & $886.57(604.22-1229.01)$ & $1926.69(1636.65-2274.61)$ \\
\hline 2017 & II 74.27 (I | $20.12-1237.63)$ & $1062.53(721.60-\mid 475.29)$ & $2236.81(1893.14-2664.53)$ \\
\hline \multirow[t]{2}{*}{ \% change 1990-2017 (UI) } & $31.4(23.0-39.6)$ & $27.7(21.5-33.5)$ & $22.7(|5.3-3| .8)$ \\
\hline & \multicolumn{3}{|l|}{ Female } \\
\hline 1990 & $929.94(882.16-1055.74)$ & $8 \mid 2.30(557.26-|| \mid 15.85)$ & $1742.24(1474.85-2036.79$ \\
\hline 1995 & $1056.20(|007.2|-\mid 169.07)$ & $843.89(574.21-|| 59.21)$ & $1900.10(1626.96-2206.21)$ \\
\hline 2000 & $963.58(936.49-1015.06)$ & $823.63(558.85-1 \mid 35.10)$ & $|787.2|(15 \mid 8.02-2093.48$ \\
\hline 2005 & 985.01 (949.78-1016.59) & 791.73 (535.74-1087.15) & $1776.75(1516.66-2073.25)$ \\
\hline 2010 & 937.22 (876.68-968.7I) & 877.59 (596.44-1206.37) & $1814.82(1533.35-2150.60)$ \\
\hline 2017 & 952.86 (9I0.2।-997.27) & $898.37(607.05-1242.25)$ & $185 \mid .24(1567.44-2195.78$ \\
\hline \% change 1990-2017 (UI) & $2.5(-10.9-10.0)$ & $6.3(-2.1-12.1)$ & $10.6(3.4-18.2)$ \\
\hline
\end{tabular}

Abbreviations: YLLs, years of life lost due to premature mortality; YLDs, years lived with disability; UI, uncertainty intervals. 
Male $-1990-2017$

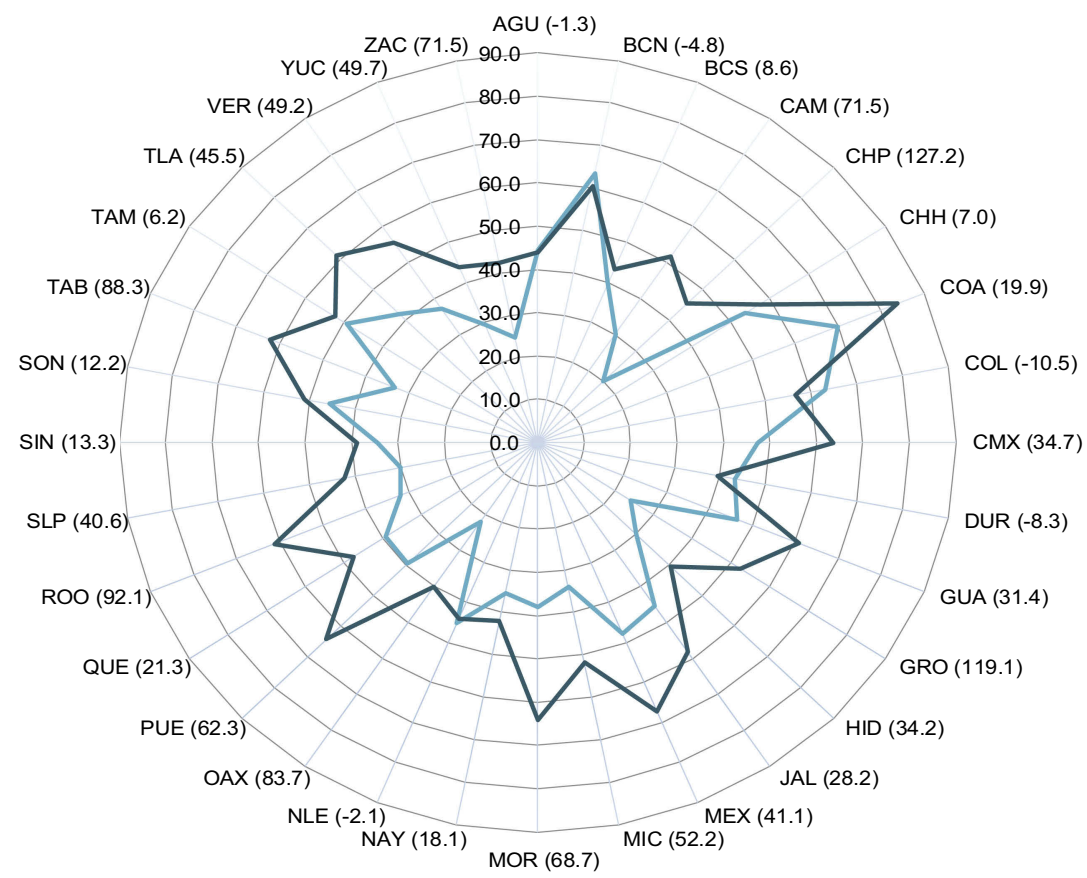

Female

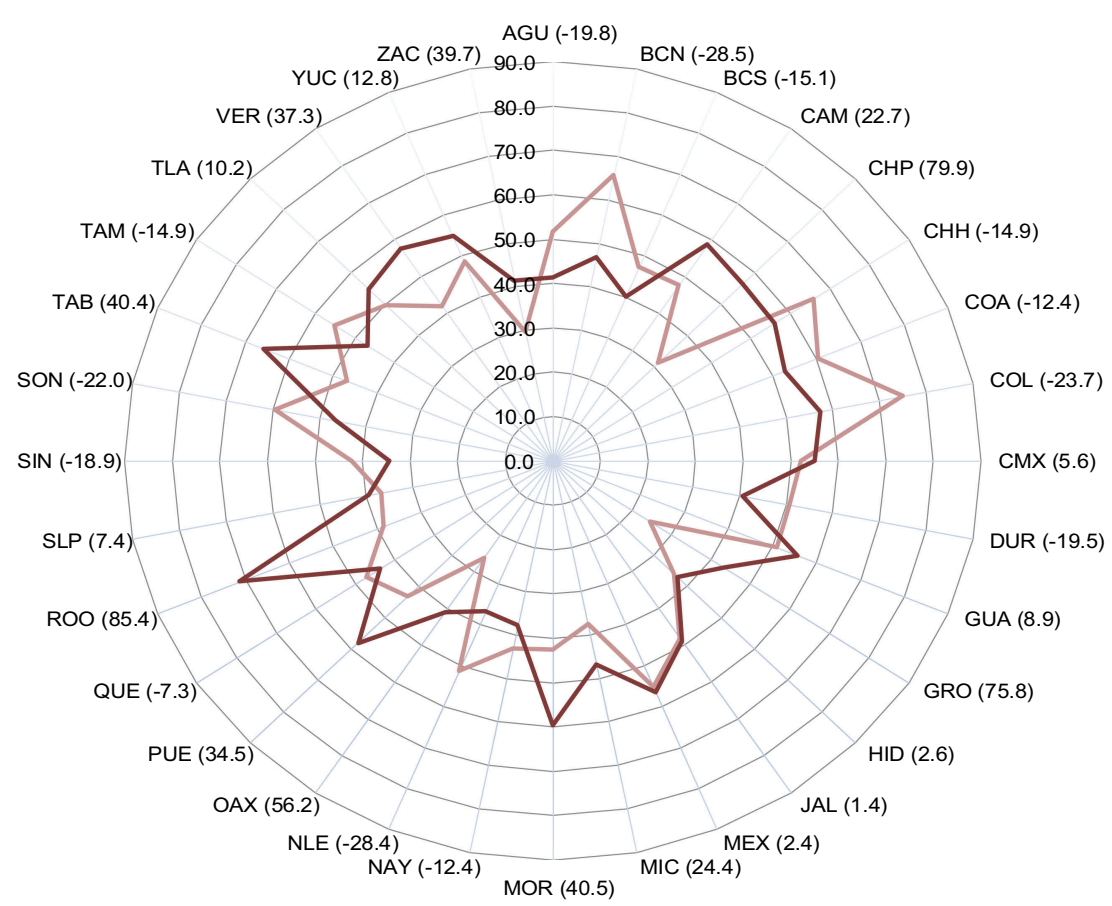

Figure 3 Age-standardized mortality rate due type 2 diabetes in Mexico, 1990 and 2017, by sex and states. Values in parentheses show the percentage change in the rate between 1990 and 2017.

Abbreviations: AGU, Aguascalientes; BCN, Baja California; BCS, Baja California Sur; CAM, Campeche; CHP, Chiapas; CHH, Chihuahua; COA, Coahuila; COL, Colima; CMX, Ciudad de México; DUR, Durango; GUA, Guanajuato; GRO, Guerrero; HID, Hidalgo; JAL, Jalisco; MEX, Estado de México; MIC, Michoacán; MOR, Morelos; NAY, Nayarit; NLE, Nuevo León; OAX, Oaxaca; PUE, Puebla; QUE, Querétaro; ROO, Quintana Roo; SLP, San Luis Potosí; SIN, Sinaloa; SON, Sonora; TAB, Tabasco; TAM, Tamaulipas; TLA, Tlaxcala; VER, Veracruz; YUC, Yucatán; ZAC, Zacatecas. 


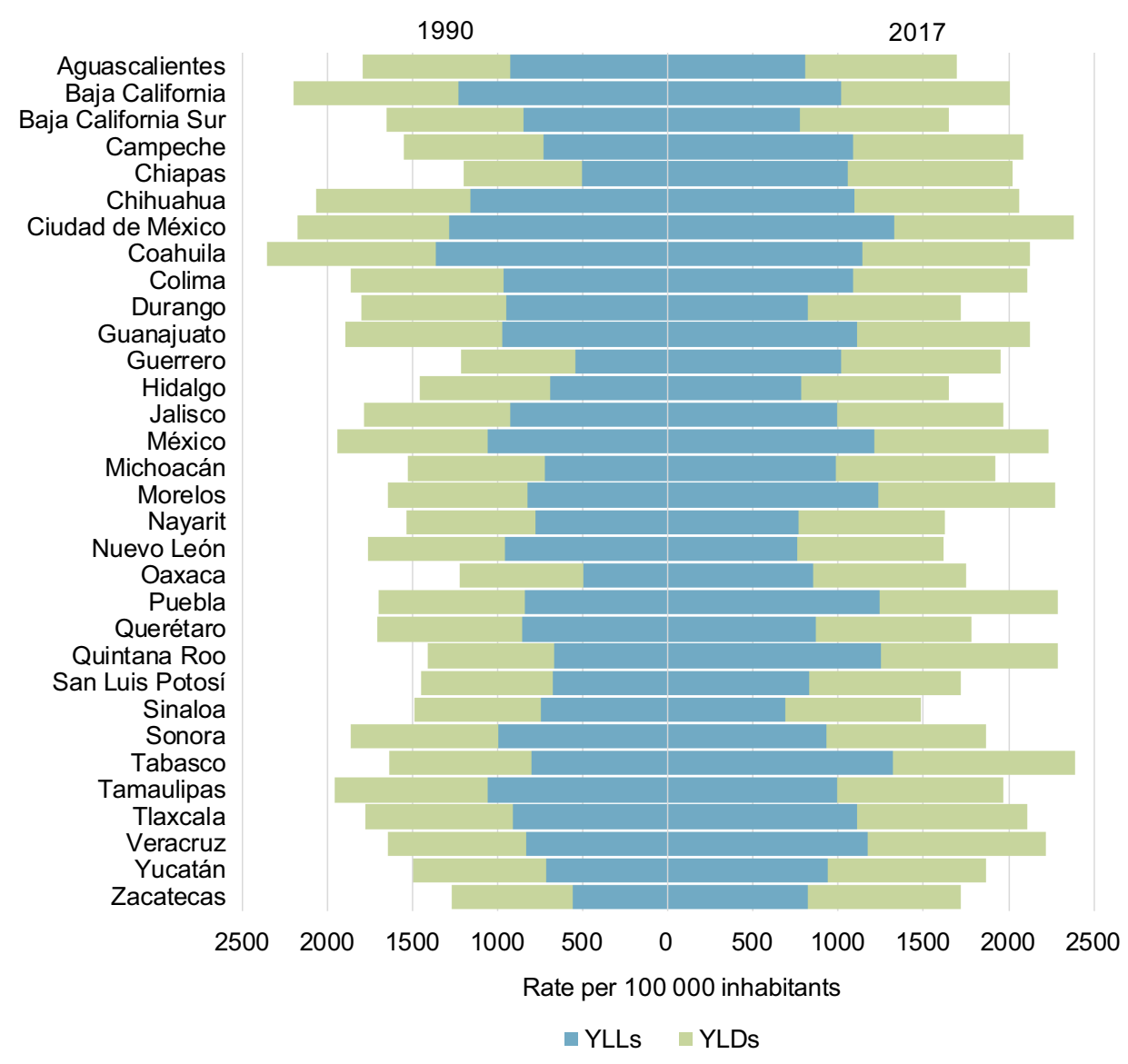

Figure 4 Age-standardized YLLs and YLDs rate due type 2 diabetes in Mexico, 1990 and 2017, by states.

Abbreviations: YLLs, years of life lost due to premature mortality; YLDs, years lived with disability.

men and 58\% in women). On the other hand, the male YLDs rate increased in all states: a situation that occurred only in Aguascalientes, Baja California, Colima and Sonora for women. Again, Chiapas, Guerrero and Quintana Roo were the regions with the highest increase in this indicator (by more than $43 \%$ in men and $32 \%$ in women).

\section{Discussion}

T2D remains an important public health problem in Mexico. However, because the available information has been limited, few studies have allowed for the kind of geographic and temporal disaggregation that this study was able to offer. To the best of our knowledge, this is the first time that information about the impact of T2D has been published that reflects the broad heterogeneity within Mexico, both premature deaths and disability, and data for men and women.

At a national level, the T2D mortality rates, YLLs and YLDs all increased consistently during the 28-year period studied. However, these changes occurred quickly in a short time. Overall mortality exhibited a dynamic behavior over time, with a constant rise since 2013. At the subnational level, the health impacts of T2D have varied within the population and have not exhibited any clearly defined geographic pattern, although it is systematically observable that the states with the highest YLLs rates also had the highest YLDs rates. Mexico City and Tabasco were the states with the highest DALYs in 2017, although states such as Chiapas, Guerrero, Oaxaca, and Quintana Roo had the most pronounced increases in all the indicators analyzed. These states also have the highest levels of poverty and marginalization in the country.

Our results show that since 2010, the male mortality rate has exceeded the female rate, inverting the epidemic's historical pattern. Although the reasons explaining this difference in T2D mortality by sex have not been deeply explored, it is possible that the change is due to the interaction of several physiological, behavioral and psychological factors that affect the course of the disease. ${ }^{20,21}$ It has been reported that men with T2D often have a lower body 


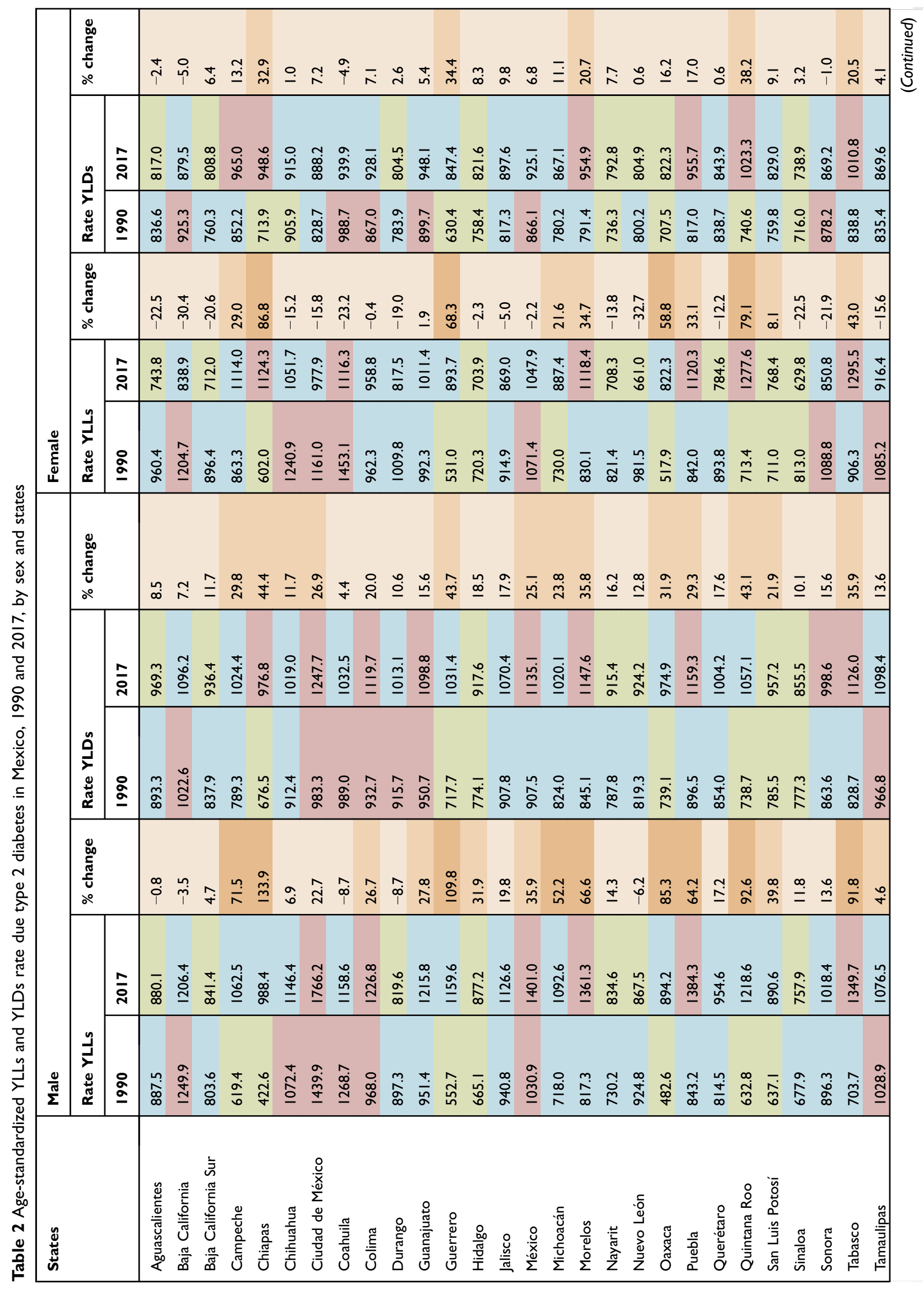




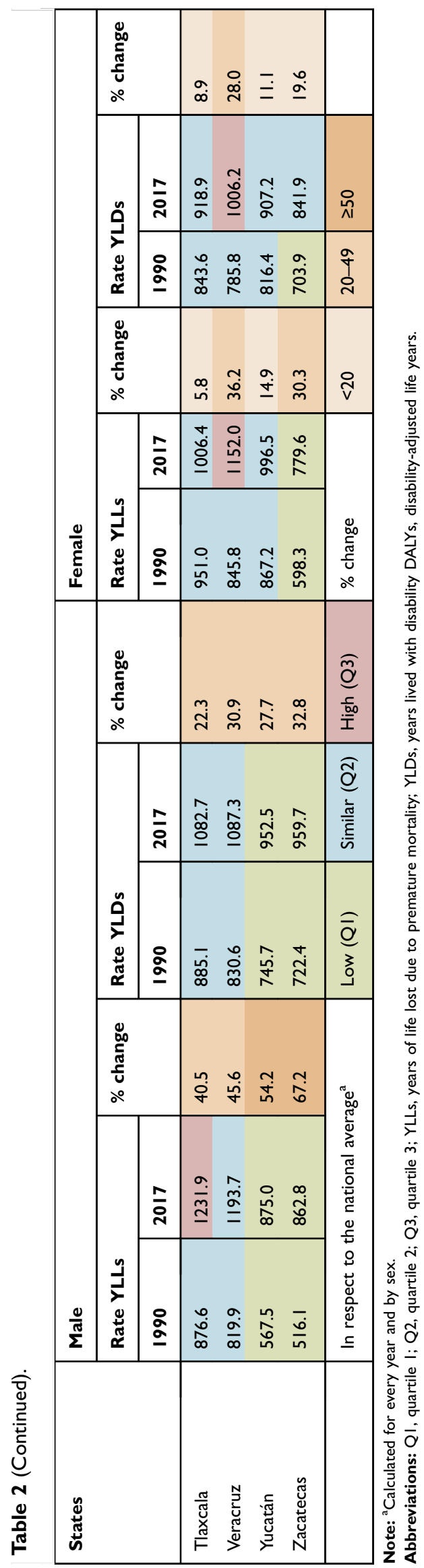

mass index than women but a higher concentration of visceral adipose tissue, which in turn generates greater insulin resistance. ${ }^{20,21}$ Men with T2D suffer more microvascular complications, while women tend to have a higher prevalence of depression, stress, and anxiety. $^{20,21}$ Data from the 2016 Halfway National Health and Nutrition Survey indicated that $3.4 \%$ of people with T2D in Mexico had macrovascular complications (such as myocardial infarction or stroke), and of these individuals, $69 \%$ were male.

All these aspects must be analyzed in specific studies to clarify the roles of sex and gender in the T2D disease burden. ${ }^{21}$ In Mexico, a key element could be to understand health service access and use trajectories and the differential effects of various health interventions on lifestyles, treatment adherence and T2D complications to assess the impact of public policies. Regardless of the efforts carried out by the health system to reduce the adverse effects of $\mathrm{T} 2 \mathrm{D}$, the results continue to be below the minimum desired standards. For example, in 2016, 87.8\% of Mexicans with T2D had some medical control of the disease, but only half took some preventive measure to avoid or delay any complication of the condition and even fewer individuals with T2D had modified their diet or increased their physical activity. ${ }^{22}$ Additionally, only $8 \%$ of Mexican males, compared to $12.9 \%$ of females, with T2D received any information about the disease. ${ }^{15}$

It has also been reported that in Mexico, in contrast to other Latin American countries, the YLLs due to T2D begin at younger ages. ${ }^{8}$ This characteristic of the epidemic could be explained by predisposing genetic factors of T2D and lifestyle risks present at a young age in the Mexican population. For example, it has been demonstrated that Mexicans have a genetic variant known as SLC16A (and other genetic variants) that increase the probability of developing T2D by $25 \%$ and explains $20 \%$ of the current prevalence. ${ }^{23-25}$ Additionally, it has been shown that the intrauterine environment conditions the occurrence of $\mathrm{T} 2 \mathrm{D}$ and that a lower birth weight or a weight higher than the adequate weight at a young age contributes to the development of different metabolic pathologies at later ages. ${ }^{12}$ Another factor associated with the increase in T2D at younger ages is an increase in obesity and overweight in younger individuals. This increase has been related to increased urbanization and the globalization of food production, which paired with a failed policy in the regulation of the market, facilitates and promotes the consumption of foods with low nutritional value from an early age. ${ }^{12}$ In 
2016, the combined prevalence of obesity and overweight in children aged 5 years or younger was $5.8 \%$ for females and $6.5 \%$ for males; in those aged 5 to 11 years, the prevalence was $32.8 \%$ and $33.7 \%$ for females and males, respectively; and in adolescents (12 to 19 years of age), the prevalence was $39.2 \%$ and $33.5 \%$ for females and males, respectively. ${ }^{26}$

In Mexico, the increase in the burden of $\mathrm{T} 2 \mathrm{D}$ is a generalized phenomenon that is predicted to continue if immediate actions are not taken to halt it. Meza and collaborators calculated that by 2050 , the prevalence of T2D diagnosed in adults older than 20 will be $13.7-22.5 \%{ }^{27}$ Looking just at adults 50 and older, the prevalence could rise from $19.3 \%$ in 2012 to $34 \%$ in $2050 .^{28}$ This increase is critical since there are enormous challenges related to reducing T2D mortality in adults aged 50 to $69 .{ }^{29}$ Mexico has a rapidly aging population, so it can be expected that T2D will continue to play a central role in the nation's epidemiological profile. ${ }^{27}$ According to the 2015 Intercensal Survey, the total population of Mexico has grown to 119,530,753 people, of whom $10 \%$ are 60 or older. ${ }^{30}$ This percentage is expected to rise to $25.1 \%$ by $2050 .{ }^{31} \mathrm{~T} 2 \mathrm{D}$ (along with homicides) is a primary culprit for the deceleration in life expectancy growth in Mexico, especially among men. ${ }^{8,10,32,33}$ It has remained at approximately 75 years since the beginning of the 21 st century, with a marginal increase of 0.3 years between 2000 and 2018. ${ }^{31}$

The gains made thus far have been insufficient. Broad, integrated policies are necessary to halt the T2D epidemic. Multidisciplinary and multisectoral work is imperative and should be directed at mitigating, decreasing and turning around the dynamic of T2D and its impacts on public health. Prevention and early identification are the most urgent challenges, as are controlling the disease and its complications. ${ }^{10,12,27}$ In this respect, two critical lines of action can be discerned. The first has to do with the advancement of methods to promote and adopt healthy lifestyles. According to the most recent national health survey (2016), 72.5\% of adults 20 and over in Mexico are overweight or obese ${ }^{15}$ - one of the highest prevalence rates in the world. ${ }^{34}$ Modifiable factors, such as lack of exercise and being overweight or obese, are those most closely associated with the risk of $\mathrm{T} 2 \mathrm{D}^{4,10,14,34-36}$ and are responsible for a large part of the burden of disease. ${ }^{19}$ A second urgent line of action is to address the disparities in healthcare coverage, access and quality. These inequities are the likely cause of the broad differences in the distribution and impact of T2D among Mexican states. Although it has been documented that there have been positive advances in ensuring equal access to medical care for diabetes, ${ }^{37,38}$ gaps remain. These disparities make the timely diagnosis and control of the disease and its comorbidities more difficult, and they raise issues related to the population's healthcare, above all for people at the lowest socioeconomic levels. ${ }^{38,39}$ However, residents of states with the highest T2D rates have limited access to medical care. Although $60 \%$ of the total T2D mortality is concentrated in these states, they have the lowest concentration of health resources such as clinics, doctors, nurses, and medical equipment. ${ }^{40}$ In Mexico, half the population does not have health insurance or is not enrolled in the Social Protection Health System known as Seguro Popular $\left(49,018,903\right.$ people) ${ }^{30}$ This is the poorest portion of the population and that with the greatest health challenges.

Finally, the information generated by using the GBD study is a useful tool to help target public policy and adequately assign resources. T2D is a potentially avoidable disease that relates to the Sustainable Development Objectives (SDO), which include the goal of using prevention and treatment methods to reduce premature deaths from non-transmissible diseases by one-third. This is a major task; a recent mortality rate projection exercise found that if current conditions do not change, Mexico will reduce premature deaths by only $25.9 \%$ by 2030 , which is far below the proposed $40 \% .{ }^{29}$ Diabetes would be reduced by only $1.8 \%$ - the lowest projected decrease. It is even estimated that the number of deaths could be 1.6-times higher than the SDO targets for $2030 .^{29}$

The strengths of this report's findings include the analysis of diabetes mortality and disability estimates in Mexico, at a national and subnational level, over the past 28 years using the GBD. The GBD is a crucial resource that can be used to define, describe and evaluate the consequences of diabetes. A limitation of this study is the possibility that information regarding diabetes may be underestimated because a high percentage of cases are not diagnosed. ${ }^{27,41}$ However, the GBD methodology offers many new statistical approaches that can reduce the challenges of trying to estimate disease burdens in terms of mortality, YLLs or YLDs, diminishing potential biases. ${ }^{16}$ 


\section{Conclusion}

T2D continues to have a dominant impact on Mexican public health, with marked disparities by sex and state. Working to reduce these health inequalities is necessary, and resources must be focused on the priority groups, for example, men, young and middle-aged adults (20-44 years), and individuals in the states with the highest index of marginalization. Strategies behind any related actions should be rooted in the demographic and epidemiological transition phase occurring in each region and be appropriate to the local social and cultural context. It is also necessary to continue to strengthen health information systems to create precise health registries at the state level.

\section{Disclosure}

The authors report no conflicts of interest in this work.

\section{References}

1. Danaei G, Finucane MM, Lu Y, et al. National, regional, and global trends in fasting plasma glucose and diabetes prevalence since 1980: systematic analysis of health examination surveys and epidemiological studies with 370 country-years and 2.7 million participants. Lancet. 2011;378(9785):31-40. doi:10.1016/S01406736(11)60679-X

2. Shaw JE, Sicree RA, Zimmet PZ. Global estimates of the prevalence of diabetes for 2010 and 2030. Diabetes Res Clin Pract. 2010;87 (1):4-14. doi:10.1016/j.diabres.2009.10.007

3. International Diabetes Federation. Diabetes Atlas 8th Edition. Available from: https://www.idf.org/elibrary/epidemiology-research /diabetes-atlas.html. Accessed November 12, 2018.

4. World Health Organization. Global report on Diabetes. Available from: http://apps.who.int/iris/bitstream/handle/10665/204871/9789241565257 eng.pdf;jsessionid=734D6766DB646134078C8669DD04F9D6? sequence $=1$. Accessed October 06, 2018.

5. Barcelo A, Arredondo A, Gordillo-Tobar A, Segovia J, Qiang A. The cost of diabetes in Latin America and the Caribbean in 2015: evidence for decision and policy makers. J Glob Health. 2017;7 (2):020410. doi:10.7189/jogh.07.020410

6. Seuring T, Archangelidi O, Suhrcke M. The economic costs of type 2 diabetes: a global systematic review. Pharmacoeconomics. 2015;33 (8):811-831. doi:10.1007/s40273-015-0268-9

7. Pan American Health Organization. Health in Americas 2017. Available from: https://www.paho.org/salud-en-las-americas-2017/. Accessed October 03, 2018.

8. Agudelo-Botero M, Davila-Cervantes CA. [Burden of mortality due to diabetes mellitus in Latin America 2000-2011: the case of Argentina, Chile, Colombia, and Mexico]. Gac Sanit. 2015;29:172-177. doi:10.1016/j.gaceta.2015.01.015

9. Institute for Health Metrics and Evaluation. Compare data visualization 2017. Available from: https://vizhub.healthdata.org/gbd-compare 1. Accessed November 10, 2018.

10. Gomez-Dantes H, Fullman N, Lamadrid-Figueroa H, et al. Dissonant health transition in the states of Mexico, 1990-2013: a systematic analysis for the Global burden of disease study 2013. Lancet. 2016;388 (10058):2386-2402. doi:10.1016/S0140-6736(16)31773-1
11. Barquera S, Campos-Nonato I, Aguilar-Salinas C, Lopez-Ridaura R, Arredondo A, Rivera-Dommarco J. Diabetes in Mexico: cost and management of diabetes and its complications and challenges for health policy. Global Health. 2013;9:3. doi:10.1186/1744-8603-9-3

12. National Academy of Medicine. [Actions to face diabetes. Posture Document] Available from: https://www.anmm.org.mx/publica ciones/CAnivANM150/L15-Acciones-paraenfrentar-ala-diabetes.pdf. Accessed November 07, 2018.

13. National Institute of Statistics and Geography. [Vital statistics mortality]. Available from: http://www.beta.inegi.org.mx/proyectos/ registros/vitales/mortalidad/. Accessed October 11, 2018.

14. Hernandez-Avila M, Gutierrez JP, Reynoso-Noveron N. [Diabetes mellitus in Mexico. Status of the epidemic]. Salud Publica Mex. 2013;55(Supp1 2):S129-S136.

15. National Institute of Public Health. [2016 Halfway National Health and Nutrition Survey. Final report of results]. Available from: https:// www.gob.mx/cms/uploads/attachment/file/209093/ENSANUT.pdf Accessed November 12, 2018.

16. Murray CJL, Lopez AD. Measuring global health: motivation and evolution of the Global Burden of Disease Study. Lancet. 2017;390 (10100):1460-1464. doi:10.1016/S0140-6736(17)32367-X

17. James SL, Abate D, Abate KH, et al. Global, regional, and national incidence, prevalence, and years lived with disability for 354 diseases and injuries for 195 countries and territories, 1990-2017: a systematic analysis for the Global Burden of Disease Study 2017. Lancet. 2018;392(10159):1789-1858.

18. Roth GA, Abate D, Abate KH, et al. Global, regional, and national age-sex-specific mortality for 282 causes of death in 195 countries and territories, 1980-2017: a systematic analysis for the Global Burden of Disease Study 2017. Lancet. 2018;392 (10159):1736-1788.

19. Stanaway JD, Afshin A, Gakidou E, et al. Global, regional, and national comparative risk assessment of 84 behavioural, environmental and occupational, and metabolic risks or clusters of risks for 195 countries and territories, 1990-2017: a systematic analysis for the Global Burden of Disease Study 2017. Lancet. 2018;392 (10159):1923-1994.

20. Malhao TA, Brito Ados S, Pinheiro RS, Cabral Cda S, Camargo TM, Coeli CM. Sex differences in diabetes mellitus Mortality trends in Brazil, 1980-2012. PLoS One. 2016;11(6):e0155996. doi:10.1371/ journal.pone. 0155996

21. Siddiqui MA, Khan MF, Carline TE. Gender differences in living with diabetes mellitus. Mater Sociomed. 2013;25(2):140-142. doi: $10.5455 / \mathrm{msm} .2013 .25 .140-142$

22. Rojas-Martinez R, Basto-Abreu A, Aguilar-Salinas CA, ZarateRojas E, Villalpando S, Barrientos-Gutierrez T. [Prevalence of previously diagnosed diabetes mellitus in Mexico]. Salud Publica Mex. 2018;60(3):224-232. doi:10.21149/8566

23. Consortium STD, Williams AL, Jacobs SB, et al. Sequence variants in SLC16A11 are a common risk factor for type 2 diabetes in Mexico. Nature. 2014;506(7486):97-101. doi:10.1038/ nature 12828

24. Sanchez-Pozos K, Menjivar M. Genetic component of type 2 diabetes in a Mexican population. Arch Med Res. 2016;47(7):496-505. doi:10.1016/j.arcmed.2016.12.007

25. Pullinger CR, Goldfine ID, Tanyolac S, et al. Evidence that an HMGA1 gene variant associates with type 2 diabetes, body mass index, and high-density lipoprotein cholesterol in a Hispanic-American population. Metab Syndr Relat Disord. 2014;12 (1):25-30. doi:10.1089/met.2013.0086

26. Shamah-Levy T, Cuevas-Nasu L, Gaona-Pineda EB, et al. [Overweight and obesity in children and adolescents, 2016 Halfway National Health and Nutrition Survey update]. Salud Publica Mex. 2018;60(3):244-253. doi:10.21149/8815 
27. Meza R, Barrientos-Gutierrez T, Rojas-Martinez R, et al. Burden of type 2 diabetes in Mexico: past, current and future prevalence and incidence rates. Prev Med. 2015;81:445-450. doi:10.1016/j. ypmed.2015.10.015

28. Gonzalez-Gonzalez C, Tysinger B, Goldman DP, Wong R. Projecting diabetes prevalence among Mexicans aged 50 years and older: the Future Elderly Model-Mexico (FEM-Mexico). BMJ Open. 2017;7 (10):e017330. doi:10.1136/bmjopen-2017-017330

29. Gonzalez-Pier E, Barraza-Llorens M, Beyeler N, et al. Mexico's path towards the sustainable development goal for health: an assessment of the feasibility of reducing premature mortality by $40 \%$ by 2030 . Lancet Glob Health. 2016;4(10):e714-725. doi:10.1016/S2214-109X (16)30181-4

30. National Institute of Statistics and Geography. [Intercensal survey 2015]. Available from: http://en.www.inegi.org.mx/proyectos/encho gares/especiales/intercensal/. Accessed November 02, 2018.

31. National Population Council. [Projections of the Population of Mexico and the States, 2016-2050]. Available from: https://datos. gob.mx/busca/dataset/proyecciones-de-la-poblacion-demexico -y-de-las-entidades-federativas-2016-2050. Accessed October 14, 2018.

32. Aburto JM, Riffe T, Canudas-Romo V. Trends in avoidable mortality over the life course in Mexico, 1990-2015: a cross-sectional demographic analysis. BMJ Open. 2018;8(7):e022350. doi:10.1136/bmjopen-2018-022350

33. Flores-Hernandez S, Saturno-Hernandez PJ, Reyes-Morales $H$, Barrientos-Gutierrez T, Villalpando S, Hernandez-Avila M. Quality of diabetes care: the challenges of an increasing epidemic in Mexico. Results from Two National Health Surveys (2006 and 2012). PLoS One. 2015;10(7):e0133958. doi:10.1371/journal.pone.0133958
34. Astudillo O. Country in focus: mexico's growing obesity problem. Lancet Diabetes Endocrinol. 2014;2(1):15-16. doi:10.1016/S22138587(13)70160-8

35. Mitchell NS, Catenacci VA, Wyatt HR, Hill JO. Obesity: overview of an epidemic. Psychiatr Clin North Am. 2011;34(4):717-732. doi:10.1016/j.psc.2011.08.005

36. Sanchez-Romero LM, Penko J, Coxson PG, et al. Projected impact of Mexico's sugar-sweetened beverage tax policy on Diabetes and cardiovascular disease: a modeling study. PLoS Med. 2016;13(11): e1002158. doi:10.1371/journal.pmed.1002158

37. Gutierrez JP, Garcia-Saiso S, Dolci GF, Hernandez Avila M. Effective access to health care in Mexico. BMC Health Serv Res. 2014;14:186. doi:10.1186/1472-6963-14-186

38. Gutierrez JP, Garcia-Saiso S, Espinosa-de la Pena R, Balandran DA. [Inequalities on indicators of chronic conditions among adults in Mexico: analysis of three health surveys]. Salud Publica Mex. 2016;58(6):666-675. doi:10.21149/spm.v58i6.7923

39. Gutierrez JP, Garcia-Saiso S, Aracena BM. Mexico's household health expenditure on diabetes and hypertension: what is the additional financial burden? PLoS One. 2018;13(7):e0201333. doi:10.1371/journal.pone.0201333

40. Durán-Arenas L, Agudelo-Botero M, Hernández L. [Population mobility in Mexico and its implications for health care]. In: Ávila JL, Hernández H, López M, editors. [Challenges of Demographic and Epidemiological Change in Mexico]. Mexico City: National Autonomous University of Mexico; 2017:273-30.

41. Bello-Chavolla OY, Rojas-Martinez R, Aguilar-Salinas CA, Hernandez-Avila M. Epidemiology of diabetes mellitus in Mexico. Nutr Rev. 2017;75(suppl 1):4-12. doi:10.1093/nutrit/nuw030

\section{Publish your work in this journal}

Diabetes, Metabolic Syndrome and Obesity: Targets and Therapy is an international, peer-reviewed open-access journal committed to the rapid publication of the latest laboratory and clinical findings in the fields of diabetes, metabolic syndrome and obesity research. Original research, review, case reports, hypothesis formation, expert opinion and commentaries are all considered for publication. The manuscript management system is completely online and includes a very quick and fair peer-review system, which is all easy to use. Visit http://www.dovepress.com/testimonials.php to read real quotes from published authors. 